\title{
Diacronie
}

Studi di Storia Contemporanea

$\mathrm{N}^{\circ} 28,4 \mid 2016$

La voce del silenzio

\section{La guerra del comandante Troncoso. Terrorismo y espionaje en Francia durante la Guerra Civil Española}

\section{Pedro Barruso Barés}

\section{OpenEdition}

Journals

Edición electrónica

URL: http://journals.openedition.org/diacronie/4772

DOI: $10.4000 /$ diacronie. 4772

ISSN: 2038-0925

Editor

Association culturelle Diacronie

Referencia electrónica

Pedro Barruso Barés, « La guerra del comandante Troncoso. Terrorismo y espionaje en Francia durante la Guerra Civil Española », Diacronie [En línea], № 28, 4 | 2016, documento 10, Puesto en línea el 29 diciembre 2016, consultado el 01 mayo 2019. URL : http://journals.openedition.org/ diacronie/4772 ; DOI : 10.4000/diacronie.4772 


\title{
Diacronie
}

N. 28 | 4|2016 La voce del silenzio: intelligence, spionaggio e conflitto nel XX secolo

\section{0/}

\section{La guerra del comandante Troncoso. Terrorismo y espionaje en Francia durante la Guerra Civil Española}

\author{
Pedro BARRUSO BARÉS *
}

El presente artículo analiza, usando como hilo conductor la figura del comandante Troncoso, los servicios de espionaje franquistas que actuaron en Francia durante la Guerra Civil española. Las actividades del servicio secreto franquista, su colaboración con los servicios secretos de Alemania e Italia y, sobre todo, la colaboración con la extrema derecha francesa son los aspectos más destacados a los que haremos referencia.

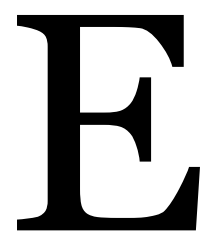

122 de marzo de 1938, el Tribunal Correccional de Brest condenó al comandante Troncoso a seis meses de cárcel a causa del fallido asalto al submarino republicano C-2, que se encontraba fondeado en el puerto de Brest $^{1}$. Terminaba de este modo una carrera que había empezado en 1936, cuando Julián Troncoso Sagredo había sido nombrado comandante militar del Bidasoa. Desde este puesto creó una organización, que con la colaboración de agentes alemanes, italianos y de ultraderechistas franceses había llevado a cabo actos de terrorismo, secuestros, intentos de asesinato, asaltos de barcos y acciones de espionaje en favor de los sublevados durante la Guerra Civil. En las páginas siguientes nos vamos a centrar en la personalidad de Troncoso y en algunas de las acciones perpetradas por su grupo de hombres, de origen variopinto y con motivaciones variadas, que durante casi dos

\footnotetext{
${ }^{1}$ El episodio del C2 y la condena a Troncoso está perfectamente estudiado en GOURLAY, Patrick, Nuit franquiste sur Brest. L'Attaque du sous-marin républicain C-2, 1937, Spézet, Coop Breizh, 2013.
} 
años operó con cierta impunidad en Francia hasta que el frustrado asalto al submarino acabó con sus correrías. Vamos a tratar de esbozar las líneas maestras de su actuación y, sobre todo, de su colaboración con agentes de la Alemania nazi y la Italia fascista. Mención aparte merecerá las relaciones con la "Cagoule" y la ultra derecha francesa. Este planteamiento nos lleva por el camino de la colaboración entre la extrema derecha francesa y los franquistas en diversos actos delictivos en Francia. A falta de investigaciones más profundas todo parece indicar que la colaboración existió por parte de la ultraderecha francesa y los agentes franquistas. Pero esta colaboración no solo se produjo con los franquistas sino también con servicios secretos de otros países. La principal relación fue con la OVRA fascista con la que colaboraron en el asesinato de los hermanos Roselli en Bagnoles de l' Orne el 9 de junio de 1937². Sin embargo, en este episodio no intervinieron los agentes franquistas. Sí que es cierto que desde la España franquista llegaron armas a la ultraderecha francesa posiblemente como compensación por la colaboración de éstos en las tareas de información, sobre todo, en el sudoeste de Francia. En esta región, limítrofe con España, es donde el comandante Troncoso libraría su particular guerra y establecería una serie de colaboraciones que vamos a mencionar brevemente en las páginas siguientes.

\section{De África al Bidasoa}

El principal protagonista de nuestras páginas va a ser el comandante de Caballería Julián Troncoso Sagredo, nacido en Valladolid el 12 de noviembre de 1895. En 1912 ingresó en la Academia de Caballería de la ciudad castellana en la que cursó estudios hasta 1917, año en el que obtuvo el empleo de teniente. Tras permanecer en varias guarniciones en la península, en 1920, fue trasladado a Marruecos donde formó parte del Regimiento de Caballería Alcantara $\mathrm{n}^{\mathrm{O}}$ 14. Integrado en el mismo tomó parte en los combates del "desastre de Annual" en julio de 1921. A consecuencia de los mismos fue capturado el 3 de agosto de 1921 al rendirse la posición de Zeluan. Dado inicialmente por muerto luego se supo que estaba preso en Axdir, donde permaneció prisionero hasta el 27 de enero de 1923, cuando fue liberado junto con otros oficiales prisioneros, y embarcado hacia Melilla en el vapor “Antonio López”.

Tras ser puesto en libertad se dirigió a Pamplona, de donde era natural su esposa Elena Cadena Iraizoz, y donde permaneció destinado hasta 1931. En su expediente personal, que se conserva en el Archivo General Militar de Segovia, llama la atención

${ }^{2}$ Sobre el asesinato de los hermanos Roselli y la implicación de la OVRA cfr. FRANZINELLI, Mimmo, Il Tentacoli dell OVRA, Torino, Bollati Boringhieri, 1999. 
que figura una anotación que señala literalmente que el día 25 de abril de 1931 Julián Troncoso «prometió por su honor este capitán servir bien y fielmente a la República, obedecer sus leyes y defenderla con las armas». Posteriormente, en junio de 1931, Troncoso se trasladó a Zaragoza donde permaneció hasta 1936.

Al comenzar la Guerra Civil se sumó a la sublevación en Zaragoza y resultó herido en los combates que se produjeron en la capital aragonesa. Convaleciente se trasladó a Pamplona y de ahí a la localidad navarra de Garayoa donde, posiblemente, su esposa de origen navarro, tuviera una casa. Mientras permanecía en dicho municipio salió en busca de una partida de republicanos que pretendían cruzar la frontera resultando nuevamente herido, esta vez en un muslo. El 6 de septiembre fue nombrado comandante militar de Vera del Bidasoa, municipio en cuya cantera se llevaron a cabo numerosas ejecuciones. El 10 de septiembre fue nombrado comandante militar de Fuenterrabía, que había sido ocupada el 4 de septiembre de 1936, y el día 12 ocupó el cargo de comandante militar de Irún y Fuenterrabía.

El 23 de diciembre de 1936, mediante una orden de la Junta de Defensa Nacional, Julián Troncoso fue nombrado «Jefe de los Servicios de Frontera del Norte de España con jurisdicción en las provincias de Navarra y Guipúzcoa, teniendo a su cargo la vigilancia con tropas de todos los Pirineos hasta Huesca; de las costas hasta el frente de guerra y de los servicios de aduanas y de represión del contrabando»3. Podemos decir que fue a partir de este momento cuando realmente comenzó la labor del comandante Troncoso como agente encubierto franquista.

Cuando se produjo el nombramiento de Troncoso los servicios de información franquistas ya habían comenzado su andadura. Antes de que Troncoso organizase los servicios de información de la Comandancia Militar del Bidasoa ya se habían llevado algunas labores organizativas. Los primeros pasos los dieron los carlistas, que desde el comienzo de la sublevación organizaron una oficina de información en Pamplona. Con anterioridad al comienzo del conflicto, a finales de 1935, se había creado en San Juan de Luz la Junta Carlista de Guerra que se ocupó de preparar todos los aspectos referentes a la sublevación y cuya actividad es bien conocida tanto por las obras de los protagonistas como por la propia documentación de la misma que se encuentra en el Archivo General de Navarra4. En el exterior el epicentro de la actividad de los

\footnotetext{
${ }^{3}$ Boletín Oficial del Estado, 66, 24 de diciembre de 1936.

${ }^{4}$ Entre la obras más importantes podemos mencionar las siguientes: BURGO, Jaime del, Conspiración y Guerra Civil, Madrid, Alianza, 1979; MAIZ, Félix B., Alzamiento en España. Diario de la conspiración, Pamplona, Editorial Gómez, 1952. En El Archivo General de Navarra se conserva el fondo "Junta Carlista de Guerra "con numerosa documentación sobre el comienzo de la Guerra Civil.
} 
tradicionalistas fue la villa "Nacho Enea" situada en San Juan de Luz y propiedad del Marqués de Caviedes. En la misma, el 19 de julio de 1936, Rafael Olazabal creó un servicio de correos entre la localidad francesa y Pamplona. Inicialmente la labor era mantener el enlace con la capital navarra por el paso de Dancharinea y labores de prensa y propaganda.

El desarrollo de los servicios de información de los sublevados en Francia vino motivado por el fracaso del golpe militar en Guipúzcoa. Al fracasar el”Alzamiento" en San Sebastián Mola se planteó la necesidad de contar con un servicio de información en Francia que contrarrestase la importante actividad en favor de los republicanos que se estaba llevando a cabo en el país vecino. Para ello, Mola, no recurrió a la organización ya creada por los tradicionalistas sino que entró en contacto con los monárquicos exiliados en Francia.

Esta preferencia de Mola, quien había pactado con los tradicionalistas poco antes, por los monárquicos merece una explicación. La razón pudo ser la calidad de los personajes implicados y las relaciones de éstos. Mientras que los tradicionalistas se centraron en el sudoeste, y su principal intención fue apoyar las actividades de la Junta Carlista de Guerra, los monárquicos se operaban fundamentalmente desde París. La personalidad de los contactos como Quiñones de León ex embajador de la monarquía o Bertán y Musitú abogado de Alfonso XIII jugaron un papel destacado. Pero la persona clave fue Francisco Moreno Zuleta, conde de los Andes. Este personaje, que había sido presidente del Banco de Madrid tras su creación por Antonio Maura y diputado conservador desde 1907, había formado parte del Directorio Civil de Primo de Rivera en el que ocupó la cartera de Economía en 19285. La razón que llevó a Mola a contactar con el conde de los Andes, según los servicios de información republicanos, fueron los contactos del conde con los servicios secretos alemanes, que se retrotraían a los tiempos de la Primera Guerra Mundial. Esta información no es del todo exacta. Cómo han puesto de manifiesto Eduardo González Calleja y Paul Aubert, en su estudio sobre las relaciones entre España y Francia durante la Primera Guerra Mundial, lo único que se ha podido documentar ha sido la presencia del conde de los Andes en el consejo de administración del Banco Hispano-Austrohúngaro creado el 23 de julio de 1918, en el que se sentaban destacados mauristas ${ }^{6}$, y que se creó con el objetivo de separar los intereses económicos del Imperio Austro-Húngaro de los de Alemania. La relación del conde de los Andes con los servicios de información alemanes parece que comenzaron

\footnotetext{
${ }^{5}$ RULL SABATER, Alberto, Diccionario sucinto de Ministros de Hacienda (s .XIX-XX), Madrid, Instituto de Estudios Fiscales, 1991.

${ }^{6}$ GONZÁLEZ CALlEJA, Eduardo-AUBERT, Paul, Nidos de espías. España, Francia y la Primera Guerra Mundial 1914-1919, Madrid, Alianza, 2014.
} 
posteriormente, durante la Dictadura de Primo de Rivera. El enlace fue Franz Von Goos, un antiguo agente de la Marina alemana y en los años treinta agente del Abwher, residente en España desde 1922. En 1935 era el consejero de prensa de la embajada alemana lo que justifica su presencia en San Sebastián en julio de 1936. Posiblemente, tras ser evacuado a Francia - junto con el resto del personal diplomático alemán -, retomó el contacto con el conde de los Andes al que conocía desde la época de la dictadura. Pero a pesar de lo anterior no parece que la actividad de los servicios de información fuese muy importante al principio del conflicto.

El acuerdo entre Mola y el conde de los Andes propició el contacto con Quiñones, quien como afirma Borja de Riquer, «era el hombre clave de los nacionales en Francia, gracias a las relaciones sociales, políticas y económicas de que disponía en aquel país»7. Quiñones sería quien integró en los incipientes servicios de información al tercer personaje, el abogado monárquico Bertrán y Musitú que sería quien realmente se hizo cargo de la creación de los servicios de información de los sublevados en Francia como he analizado en anteriores estudios ${ }^{8}$. También parece confirmarse la presencia del Juan March, el financiero mallorquín, en los primeros pasos de los servicios de información lo mismo que otros personajes como Joan Estelrich. Este último sería una pieza destacada en los servicios de información al ser el responsable de la Oficina de Prensa y Propaganda que editó desde febrero de 1937 el Boletín de Información Española.

Pero volviendo atrás en el tiempo debemos hacer referencia a un hecho fundamental para el conocimiento del desarrollo de los servicios de información de los sublevados. En agosto de 1936, en una granja denominada «La Férme»9 propiedad de Madame Gironde, se reunieron el conde de los Andes, Von Goss, Bertrán y Musitú además de otros personajes. En la misma se tomaron varios acuerdos de importancia. El primero de ellos fue trasladar y centralizar todos servicios a Nacho Enea. En segundo lugar que dicha villa fuese alquilada por el ciudadano francés Iñigo de Bernoville, miembro de la organización ultraderechista francesa «Croix de Feu», hermano del escritor Gaëtan Bernoville. Se acordó también la creación de un servicio de propaganda, socorro, información y, lo que es más importante, un comando de acción al frente del cual se sitúa José María Marcet y Vidal, un militar destinado en Zaragoza y que se encontraba en Francia sin que sepamos exactamente cuál era su cometido. De

\footnotetext{
7 RIQUER, Borja de, El último Cambó, 1936-1947. La tentación autoritaria, Barcelona, Grijalbo, 1997.

${ }^{8}$ BARRUSO BARÉS, Pedro, El frente silencioso. La Guerra Civil española en el sudoeste de Francia, Alegia, Hiria, 2001.

${ }^{9}$ DUO, Gonzalo, «Memoria de Haranederrea, Ascain (Pirineos Atlánticos), albergue incógnito de los Borbones carlistas», in Boletín de Estudios del Bidasoa, 24, 2006, pp.367-516.
} 
este modo, para agosto de 1936, los agentes de los sublevados ya habían tomado la decisión de contar con un grupo dispuesto a actuar de manera violenta contra los intereses republicanos en Francia como veremos más adelante.

Pero no solo los sublevados se organizaban. Los republicanos también comenzaron a crear una mínima infraestructura pero ésta no se desarrolló hasta septiembre de 1936, tras la formación del Gobierno Largo Caballero. Las primeras labores llevadas a cabo por los republicaos fueron de tipo propagandístico, tratando de contrarrestar la propaganda de los sublevados a la que ya hemos hecho referencia. En lo que se refiere a los servicios de información la primera organización que podemos mencionar fue la organizada por el pintor socialista Luis Quintanilla, que tenía la dirección de su servicio en Biarritz y contaba con agentes en San Juan de Luz, Bayona, Saint Jean-Pied-de Port, Pau, Burdeos, Niza y Toulouse. Esta red contó con el apoyo de dos policías franceses, a sueldo de Quintanilla, pero que a la vez eran agentes de los servicios secretos franceses. De todos modos la actuación de Quintanilla duró poco ya que cuando Araquistain abandonó la Embajada en París, en mayo de 1937, el organizador de la red cesó en sus funciones y se exilió en América donde continuó su carrera artística.

Por su parte las autoridades francesas también tomaron cartas en el asunto ante la proliferación de servicios secretos que se estaba llevando a cabo. Además de la infiltración en la red Quintanilla que ya hemos mencionado el gobierno francés mantuvo la vigilancia sobre «Nacho Enea» y el 26 de septiembre de 1936 la policía francesa llevó a cabo un registro a consecuencia del mismo Bernoville fue acusado de falsificación de pasaportes, tenencia de armas y explosivos y violación de las leyes francesas de radiodifusión. El objetivo del registro era localizar una supuesta emisora de radio instalada en «Nacho Enea» pero ésta no fue localizada. A pesar de la actuación de la policía francesa, como reconoce el embajador norteamericano Claude G. Bowers, al día siguiente del registro la actividad de la villa volvió a la normalidad ${ }^{10}$. De todos modos las circunstancias iban cambiando y era necesario acometer una reorganización de los servicios de información de ambos bandos.

\section{La Comandancia del Bidasoa entra en escena}

Retomando el hilo de nuestra narración hemos visto como el comandante Troncoso había sido nombrado el 23 de diciembre de 1936 «Jefe de los Servicios de Frontera del Norte de España», con jurisdicción en una amplia zona, y a la vez afirmábamos que fue

${ }^{10}$ BOWERS, Claude G., Misión en España (1933-1939). En el umbral de la Segunda Guerra Mundial, Barcelona, Grijalbo, 1978, p. 303. 
a partir de ese momento cuando comenzó su actividad como agente encubierto. Además, esta circunstancia coincide con la reordenación de los servicios tanto republicanos como de los sublevados.

Tras el nombramiento de Troncoso se dotó a a la Comandancia de una oficina de prensa, un gabinete de claves y uno de cartografía a la vez que se destacaron agentes de la misma en Hendaya, San Juan de Luz, Bayona y La Rochelle. Pronto la Comandancia decidió pasar a la acción contra el espionaje republicano y concretamente contra la «Red Quintanilla». La actuación se concretó en la detención de una ciudadana francesa, Jacqueline Desiret, casada con un pastelero de Hendaya llamado Alonso y que colaboraba con la red de información republicana. Al parecer Desiret fue atraída a España y detenida por los hombres de Troncoso en noviembre de 1936. Simultáneamente agentes de la Comandancia registraron su domicilio sin que lograran información sobre la red por lo que Desiret fue puesta en libertad. En enero de 1937 entró nuevamente en España y fue detenida otra vez. Esta vez parece que Desiret se iba a entrevistar con un oficial falangista que había conocido en Biarritz. A partir de ese momento se produjo un episodio confuso. Por una parte parece que el contacto con el oficial falangista tenía como objetivo recabar información pero la Comandancia hizo correr el rumor de que una mujer había sido fusilada en San Sebastián por espionaje. Todo parece indicar que las autoridades franquistas quisieron hacer creer a Quintanilla que la fusilada había sido su amiga Desiret lo que pudo sumir al pintor republicano en un estado de desmoralización que pudo precipitar su abandono de las labores de información que desarrollaba.

Pero las actividades de la Comandancia no eran bien vistas por todos los partidarios de los sublevados. Las quejas provenían tanto de las autoridades militares como de los tradicionalistas y se dirigían hacia la actuación de Troncoso y hacia el personal de la Comandancia. La Comandancia Militar de Guipúzcoa se quejaba de la autonomía de Troncoso en la cuestión del regreso de los refugiados, una cuestión clave para las nuevas autoridades, pero sobre todo se dirigían contra el personal de la Comandancia. Éste estaba integrado por cuatro militares, además de Troncoso, y siete civiles que se ocupaban de las tareas administrativas. La autoridad militar de San Sebastián consideraba que entre el personal de la Comandancia había «republicanos lerrouxistas» o un acusado de «tener un hermano rojo que antes del movimiento hacía exaltadas manifestaciones de izquierdismo». Las acusaciones también hacían referencia a cuestiones de delincuencia común, como cuando acusaban a uno de los agentes de la Comandancia de «traficante de cocaína que vendía en los cabarets de San 
Sebastián» ${ }^{11}$. Pero tampoco el personal militar estaba exento de críticas. Un oficial de complemento, afecto a la Comandancia, era considerado «un chico bien y completamente inútil pues no ha trabajado en su vida» ${ }^{12}$. Por parte tradicionalista las quejas se dirigían hacia la supuesta connivencia de los hombres de la Comandancia con los nacionalistas de Irún. Las críticas también incluían una cierta queja por la escasa influencia de los tradicionalistas en la Comandancia. En un informe de la Junta Carlista de Guerra en el que se dice que «en la aduana de Irún y Behobia debe haber algún requeté que por lo menos fiscalice a nuestro favor y el de la causa la frontera» ${ }^{13}$. Otra de las críticas de los tradicionalistas hacía referencia a las relaciones de Troncoso, a quien acusaban de querer «entenderse directamente con la Secretaría General del Estado saltándose todas las demás organizaciones del mismo» ${ }^{14}$, o lo que es lo mismo, tratar directamente con Nicolás Franco con el que Troncoso tenía una especial relación.

Esta autonomía, los importantes apoyos con los que contaba, el interés de la Junta Técnica por controlar la frontera y, posiblemente, el propio carácter del comandante Troncoso favoreció que las acciones de los hombres de la Comandancia fuesen cada vez más audaces. El componente del carácter de Troncoso no lo debemos desdeñar y para muestra podemos mencionar un informe del Ministerio de Asuntos Exteriores en el que se dice lo siguiente:

El 29 de julio [de 1937] a las 13,15 llegó al puente internacional de Hendaya en compañía de dos personas más, el ex comandante Troncoso, portador de un ramo de flores. El carabinero de servicio le hizo observar que estaba prohibida la importancia (sic) en Francia de flores naturales y el ex comandante replicó que como era el día de Santa Marta, iba a ofrecer un descomunal ramo de flores a Doña Marta Herbette, esposa del embajador de Francia en España. Es de consignar que el ramo de flores iba adornado con banderines con los colores de España monárquica, Italia, Alemania y Portugal ${ }^{15}$.

Esto, que no pasa de ser una anécdota nos permite hacer una pequeña referencia a otro de los personajes decisivos en la guerra silenciosa que se libró en la costa vasco-

\footnotetext{
${ }^{11}$ Archivo General Militar de Ávila-Documentación Nacional (AGMA-ZN) leg.11, exp. 13 y Leg.11, exp. 27.

${ }^{12}$ AGMA-ZN, Leg.11, exp. 27.

${ }^{13}$ Archivo General de Navarra- Junta Carlista de Guerra (AGN-JCG), caja 29.299, informe del 16 de octubre de 1936.

${ }^{14}$ AGN-JCG, caja 20.301, exp.8.

${ }^{15}$ Archivo Ministerio de Asuntos Exteriores (AMAE), Fondo Barcelona, caja 44.
} 
francesa. Jean Herbette ${ }^{16}$, embajador de Francia en España desde mayo de 1931, jugó un papel destacado en la Guerra Civil. Partidario de los republicanos en los primeros momentos del conflicto, posteriormente se inclinó por los sublevados aunque llevó a cabo muchas gestiones humanitarias ante uno y otro bando. La relación de Herbette con Troncoso, a parte de la anécdota que hemos mencionado anteriormente, tuvo gran importancia. Gran parte de las relaciones de los sublevados con el gobierno francés pasaron por Herbette y tuvo una destacada influencia en la opinión pública francesa, en gran medida partidaria de los sublevados, y muy mediatizada por la presión de la ultraderecha.

Pero volviendo a las actuaciones de Troncoso, y los hombres de la Comandancia Militar del Bidasoa, debemos hacer referencia a las actividades que llevaron a cabo. La primera de ellas, y que logró un éxito parcial, fue la captura del avión de «Air Pyrénées ${ }^{17}$. Se trataba de una compañía aérea creada por el Gobierno vasco y que realizaba tres vuelos diarios entre Biarritz y Bilbao trasladando correspondencia y enviados del Gobierno vasco desde Francia. La iniciativa de crear la línea aérea correspondió a dos miembros del PNV con la colaboración del cónsul en Bayona y Hendaya Pedro Lecuona. Los vuelos de «Air Pyrénées» ya habían sido objeto de ataques de la aviación franquista pero la operación fundamental contra la aerolínea vasca se llevó a cabo el 21 de junio de 1937 cuando se forzó el aterrizaje del avión en la playa de Zarauz. Para llevar a cabo la captura del avión los servicios franquistas contactaron con José Yanguas Yáñez, piloto que contaba con la confianza del ejecutivo autónomo. El pasaje del vuelo estaba formado por Georges Rougé, antiguo militar francés reconvertido en comerciante de pastas que supuestamente se dirigía a Bilbao para negociar la compra de un partida por parte del Gobierno vasco; el jefe de administración de la Consejería de Sanidad, y secretario particular del consejero de Sanidad Alfredo Espinosa, Emilio Urbierna; el funcionario del Gobierno vasco Eugenio Urgoiti; el mecánico Pablo Martínez; el militar José Aguirre y el propio Consejero de Sanidad, el republicano Alfredo Espinosa. Todo parece indicar que la captura del avión

${ }^{16}$ Sobre Herbette cfr. DENÉCHÈRE, Yves, Jean Herbette (1878-1960): journaliste et ambassadeur, Bruxelles, PIE-Peter Lang, 2003; BARRUSO BARÉS, Pedro, JIMÉNEZ DE ABERÁSTURI CORTA, Juan Carlos, El comienzo de la Guerra Civil en Euskadi a través de los documentos diplomáticos franceses. Los informes del embajador Jean Herbette (San Sebastián: julio-octubre de 1936), San Sebastián, Fundación Kutxa, 2011.

${ }^{17}$ Sobre la captura del avión resulta imprescindible la consulta de SEBASTIÁN GARCÍA, Lorenzo, «Alfredo Espinosa Orive (1903-1937): Detención, procesamiento y ejecución de un consejero del Gobierno Vasco», in Sancho el sabio: Revista de cultura e investigación vasca, 28, 2008, pp. 213-246. 
fue una trampa ya que como se desprende de que en la playa de Zarauz se hubiese balizado la zona del aterrizaje, se hubiesen retirado los toldos y se había dado orden a los buques franquistas en la zona de no disparar contra el avión. Lorenzo Sebastián, en su estudio sobre la captura de Espinosa, señala además de la implicación de Yanguas, la del mecánico Pablo Martínez. Tal como indica Sebastián fue, junto con el piloto, uno de los dos pasajeros que no fueron incomunicados cuando fueron trasladados a Vitoria los detenidos. Según indica Ángel Ojanguren Pablo Martínez, natural de Lequeitio, estaba afiliado a la UGT «para poder circular libremente por la calle» ${ }^{18}$. Por su parte Yanguas fue conducido esa misma noche a Toulouse acompañado de Joaquín Goyoaga, gerente de una empresa importadora de vehículos en la que trabajaba Yanguas. El objetivo de ese viaje era recuperar unas cajas con joyas de familias nacionalistas y de la Virgen de Begoña depositadas en la Banca Courtoise ${ }^{19}$. Finalmente el 25 de junio de 1937 fue puesto en libertad. El 19 de julio pasó a Francia en un canje de prisioneros y, según se desprende del informe del Servicio Especial del Consulado de Hendaya, Yanguas no se trasladó a Paris sino que lo hizo a Toulouse, donde permaneció un periodo de dos meses hasta que el prefecto le prohibió la residencia en la ciudad tras lo que se trasladó a Montauban, A finales de 1937, según las fuentes republicanas, decidió marcharse a México donde se le pierde la pista ${ }^{20}$.

Peor suerte corrieron el resto de pasajeros del avión. Espinosa y Aguirre fueron fusilados el 26 de junio de 1937 en Vitoria. Eugenio Urgoiti y Emilio Ubierna fueron también condenados a muerte en el mismo consejo de guerra que Espinosa pero sus penas fueron conmutadas. En los años cuarenta sus sentencias fueron revisadas y reducidas a seis años y un día. En 1942 Eugenio Urgoiti seguía en el penal de Burgos y fue puesto en libertad en 1945 tras pasar por los presidios de Cáceres y Bilbao. Por su parte Emilio Ubierna desconocemos cuando fue puesto en libertad ${ }^{21}$. George Rougé fue puesto en libertad debido a las gestiones diplomáticas del embajador Herbette ${ }^{22}$.

En la captura del avión de «Air Pyrénées» Troncoso contó con la colaboración de la Comandancia Militar de Zarauz. Se da el caso curioso que en la misma, con motivo de

\footnotetext{
${ }^{18}$ OJANGUREN, Ángel, Ángel Ojanguren, de procónsul británico en Bilbao a delegado vasco en Roma, Bilbao, Fundación Sabino Arana, 1990, p. 121.

${ }^{19}$ SEBASTIÁN GARCÍA, Lorenzo, op. cit., p. 232.

${ }^{20}$ Archivo del Ministerio de Asuntos Exteriores. Fondo Barcelona, caja 47. Informe del 30 de diciembre de 1937.

${ }^{21}$ Los expedientes de revisión de sus condenas se pueden consultar en el Archivo General Militar de Guadalajara (AGMGU), Sección Penas de Muerte Conmutadas. El de Eugenio Urgoiti Echeverría (11/764) y el de Emilio Ubierna Rivera (29/2148). En el Archivo General de la Administración (AGA) se pueden consultar sus fichas penitenciarias

${ }^{22}$ Las gestiones de Herbette para liberar a Rougé en Centre des Archives Diplomatiques de Nantes (CADN) Madrid Ambassade, carton 596.
} 
la campaña de Vizcaya, como narra William A. Christian en su estudio sobre las visiones de Ezkioga ${ }^{23}$, se organizó una sesión para intentar que los visionarios tuvieran una visión de por donde era más fácil atacar el «Cinturón de Hierro» que protegía la capital vizcaína. Como se puede ver los agentes franquistas recurrían a cualquier tipo de colaboración para lograr sus objetivos.

\section{El asalto a los barcos}

Analizadas algunas de las acciones de los hombres de Troncoso debemos centrarnos en sus acciones más importantes y en las que lograron los mayores éxitos como fue el asalto y captura de barcos republicanos en puertos franceses o en alta mar.

Uno de los principales objetivos de los sublevados era el interrumpir el comercio entre Europa y la zona republicana con el fin de evitar que las tropas republicanas pudieran recibir armas, municiones y pertrechos. Tras la ocupación de San Sebastián, en septiembre de 1936, el puerto de Pasajes se convirtió en una importante base desde la que atacar el tráfico marítimo republicano. La primera víctima de las operaciones de los sublevados fue el buque «Galerna», un antiguo bacaladero que fue empleado desde septiembre de 1936 para el transporte de personas y mercancías entre Bayona y Bilbao. En el transcurso de su tercer viaje, el 15 de octubre de 1936, fue capturado por cuatro bous al servicio de los sublevados. Como señala Juan Pardo la captura del buque respondió a la colaboración de parte de la tripulación con los rebeldes y en concreto el comandante de la nave y el primer oficial habían pactado la entrega de la misma ${ }^{24}$. La captura del barco tuvo una gran repercusión en la prensa de la zona controlada por los sublevados. El 17 de octubre de 1936 «El Diario Vasco» dedicó un reportaje a la captura del barco destacado que entre los prisioneros capturados se encontraba el sacerdote y propagandista nacionalista José Ariztimuño «Aitzol». Todos los prisioneros fueron fusilados en el cementerio de Hernani, una localidad cercana a San Sebastián donde se llevaban a cabo las ejecuciones, con la sola excepción del ciudadano francés Jean Pelletier, al que las gestiones del embajador francés Jean Herbette lograron liberar²5.

Tras el «Galerna» los ataques contra los barcos continuaron. El siguiente objetivo fue el mercante «Mar Rojo», al que le colocaron un explosivo en las calderas tras lo cual fue capturado. Lo mismo ocurrió con el petrolero «Campoamor» que se encontraba

${ }^{23}$ CHRISTIAN William A., Las visiones de Ezkioga. La II República y el reino de Cristo, Madrid, Ariel, 1997.

24 PARDO SAN GIL, Juan, «La flota de arrastre de Pasajes durante la Guerra Civil (1936-1939)», in Bilduma, 4, 1990, pp. 47-80.

${ }_{25} \mathrm{CADN}$, Madrid Ambassade, carton 576. 
fondeado, cargado de petróleo, en el puerto de Le Verdon. Para su captura se organizó un grupo de asalto formado por el capitán Miguel Ibáñez de Opácua, Manuel Orendain, Emiliano Baraibar y el jefe local de FET y de las JONS de Irún. Este grupo contó con la colaboración de León Pardo, un agente de aduanas de Hendaya. Para capturar el barco los agentes franquistas organizaron un baile en la Pointe de Grave. Según se narra en un informe del Servicio Especial del Consulado de Hendaya los agentes franquistas organizaron el baile para reunir

\begin{abstract}
A los marinos leales con mujeres de la vida que fueron captándoles la voluntad. Casi todos los días nuestros inocentes marinos saltaban a tierra para frecuentar los restaurantes y cabarets donde estas mujeres les esperaban, Un día convenido por los fascistas se aprovechó uno de esos bailes nocturnos en que no quedaban a bordo más que la oficialidad ganada por los fascistas y marinos sin color para entrar a bordo del Campoamor un grupo de fascistas, al frente de los cuales iba un capitán de la marina rebelde y sacar el barco tranquilamente dirigiéndolo al puerto de Pasajes en donde entró al atardecer del sábado 10 de julio[de 1937]26.
\end{abstract}

El éxito con el «Campoamor» llevó a los hombres de la Comandancia del Bidasoa a tratar de apoderarse de nuevos objetivos de más calado como eran los destructores «José Luis Díez» y «Císcar», los únicos navíos de guerra de cierta importancia con que contaban los republicanos en el Cantábrico. Los servicios de seguridad republicanos mantenían una discreta vigilancia sobre el comandante de éste último -Juan Antonio Castro Eizaguirre ${ }^{27-}$ hijo del que fuera presidente de la Diputación de Guipúzcoa y Gobernador Civil de Vizcaya, el republicano Luis Castro Casal. Éste había sido autorizado por los franquistas para regresar a su Tolosa natal lo que levantó recelos de los republicanos quienes consideraban que, en contrapartida por el regreso de su padre, el comandante podía entregar el buque. Finalmente las sospechas no se cumplieron y el «Císcar» fue hundido por la aviación franquista en el puerto de Gijón el 20 de septiembre de 1937.

\footnotetext{
${ }^{26}$ AMAE, Fondo Barcelona, caja 44.

27 Tras el hundimiento del «Císcar» Castro se trasladó a Cartagena y luego a Barcelona desde donde pasó a Francia. Comenzada la Segunda Guerra Mundial fue internado en el campo de Gurs, de donde escapó. Ante la llegada de las tropas alemanas partió de San Juan de Luz en dirección a las costas de Irlanda. Se unió a las fuerzas de la Francia Libre y combatió en el Pacífico a bordo del destructor francés "Triomphant", curiosamente uno de los buques franceses que estuvo patrullando en el Cantábrico durante la Guerra Civil. Cfr. BARRUSO BARÉS, Pedro, JIMÉNEZ DE ABERÁSTURI, Juan Carlos, El comienzo de la Guerra Civil en Euskadi a través de los documentos diplomáticos franceses. Los informes del embajador Jean Herbette (San Sebastián: julio-octubre de 1936), San Sebastián, Fundación Kutxa, 2011.
} 
Por su parte el «José Luis Díez» también era vigilado por agentes republicanos. El motivo fue el informe de un agente republicano, días antes de que zarpase hacia Inglaterra, que recogía la pretensión de los agentes franquistas de hacerse con el buque. Este navío ya había sufrido un sabotaje en marzo de 1937 tras haber efectuado reparaciones en el puerto de Burdeos. Pese a que el comandante del buque y cinco oficiales desertaron el barco siguió fiel a la República. En agosto de 1938 partió hacia el Mediterráneo con el antiguo comandante del «Císcar» al mando. El 27 de agosto de 1937, tras ser atacado por el crucero sublevado «Canarias» se refugió en Gibraltar donde permaneció hasta el 30 de diciembre de 1938 fecha en la que, tratando de escapar, acabó varado en la playa.

\section{El asalto al C-2. El final de la historia}

Las actuaciones del grupo de Troncoso iban a finalizar el 18 de septiembre de 1937. Ese día se produjo el fallido asalto por parte de los hombres de la Comandancia de Irún al submarino republicano C-2 que se encontraba en el puerto de Brest ${ }^{28}$.

Las intenciones de Troncoso eran que los sublevados se apoderasen de un submarino republicano refugiado en Francia, al carecer la flota sublevada de ellos. Dos sumergibles, el C-4 en Le Verdon y el C-2 en Brest, fueron sus objetivos. Los agentes franquistas intentaron en primer lugar apoderarse del C-4 y para ellos contactaron con el comandante de mismo, Jesús Miguel Las Heras, quien aceptó pasarse a las filas de los sublevados, no sin antes sabotear el submarino y destruir varias piezas imprescindibles para la navegación. Ante esta circunstancia los hombres de Troncoso colocaron en el objetivo al submarino C-2 refugiado en el puerto de Brest. El plan para apoderarse del submarino fue el mismo empleado en otras ocasiones. Se trataba de conseguir que los oficiales se pasaran de bando ofreciéndoles una determinada cantidad de dinero. Si esto no funcionaba la segunda opción era asaltar el navío, al igual que había ocurrido en otras ocasiones, neutralizando a la tripulación. En esta ocasión los hombres de Troncoso optaron por el asalto. Para ello se organizó un comando en el que, además de Troncoso, se integraron Robert Chaix, Rafael Parella, Manuel Orendain José María Gabarain y Salvador Serrats. Además de éstos apoyaron la operación León Pardo, agente de aduanas de Hendaya y el marqués de Linares. Del grupo asaltante queremos destacar la personalidad de los dos franceses; Robert Chaix y León Pardo.

${ }^{28}$ Sobre el asalto al submarino C-2 resulta imprescindible la consulta de la obra de Patrick Gourlay ya citada. 
Ambos eran miembros del Partido Social Francés (PSF) del coronel La Rocque. Chaix era responsable del PSF en San Juan de Luz y es posible que fuera miembro de la Cagoule. Por su parte León Pardo también pertenecía a la Croix de Feu y fue colaborador de los alemanes durante la Segunda Guerra Mundial29.

Tras prolijos preparativos, y muchas idas y venidas de los hombres de Troncoso, éstos decidieron pasar a la acción. El plan era sencillo. Aprovechando un día en que parte de la tripulación se encontraba en tierra los hombres del comando se acercarían en barca al submarino. Con lo que no contaba Troncoso es que, al parecer, dos miembros del llamado Servicio de Información y Coordinación (SIC) de la CNT se habían infiltrado en las filas de los hombres de Troncoso. Según las fuentes anarquistas dos agentes, X-9 y X-12, entraron en contacto con un miembro de la tripulación Augusto Diego a quien pusieron al día de los planes de los franquistas.

Los asaltantes, en un primer momento, lograron reducir a la tripulación pero Agusto Diego se parapetó en la torreta del submarino. Uno de los asaltantes, Manuel Orendain, trató de reducirlo pero Diego lo abatió de un disparo. Esto hizo que el resto de asaltantes se retirara sin poder apoderarse del submarino. Los asaltantes emprendieron la huida hacia la frontera española. La policía francesa detuvo a varios de ellos cerca de la frontera. Los arrestados fueron Manuel Orendain, Salvador Serrats y Rafael Parella. Troncoso, según sus propias declaraciones, pasó a España escondido en el maletero del coche del embajador de Argentina.

La crisis del C-2 provocó un serio incidente diplomático entre la España franquista y Francia. Al día siguiente de la detención de los miembros del comando Troncoso se presentó ante el comisario especial de Hendaya exigiendo la liberación de sus hombres. Tras numerosas consultas a París fue el propio ministro de Interior, el socialista Marx Dormoy, el que ordenó la detención de Troncoso pese a las amenazas de éste de que su detención equivaldría a una declaración de guerra entre Francia y la España franquista. La decisión de detener a Troncoso, y la constancia por parte de las autoridades francesas de la colaboración de éste con la Cagoule, se produjo en la coyuntura de las crisis de los cagoulards en Francia. Recuérdese que una semana antes del ataque al C-2 se había producido la explosión en la sede de la patronal francesa, en la que murieron dos policías, en junio habían sido asesinados los hermanos Roselli y en enero miembros de la Cagoule habían asesinado en el Bois de Boulogne al banquero ruso Navachine. Todos estos acontecimientos podemos suponer que hicieron que la postura del Gobierno francés fuese de mayor dureza y decidiera acabar con las andanzas de los

${ }^{29}$ Una amplia documentación sobre los miembros del comando en Archivo Nacional de Francia (ANF)- Serie F. 
hombres de la Comandancia en territorio galo. De todos modos las consecuencias del asalto no fueron demasiado graves. Los detenidos permanecieron encarcelados hasta marzo de 1938.

El 22 de marzo de 1938 un tribunal de Brest condenó a Troncoso, Serrat y Orendain a seis meses de prisión. Chaix fue puesto en libertad al anunciarse el veredicto y Orendain, tras ser liberado en Brest fue conducido a Bayona donde debía comparecer ante el juzgado por una cuestión posesión de armas y explosivos. El 26 de marzo Troncoso y Serrats fueron expulsados de Francia por Hendaya. Con su expulsión de Francia se puso fin a la carrera como agente encubierto de Julián Troncoso. Tras su regreso a España fue cesado de su cargo de Comandante Militar del Bidasoa y trasladado al frente de Cataluña. La prensa republicana le dio por muerto en marzo de 1938 sin embargo la noticia resultó falsa. Tras la Guerra Civil Julián Troncoso fue nombrado presidente de la Federación Española de Fútbol por el Delegado Nacional de Deportes general Moscardó. Igualmente fue vicepresidente del Real Madrid y entre 1961 y 1964 fue procurador en Cortes por el Sindicato Nacional del Transporte que presidía al ser un empresario del sector. Su papel al frente de un comando durante la Guerra Civil quedaba muy atrás aunque todavía en 1970, en las páginas del diario «ABC»30 recordaba las actividades de éste grupo lo que es una muestra de la importancia de las actuaciones de los hombres de la Comandancia Militar del Bidasoa.

${ }^{30} A B C, 30$ de enero de 1970, p.35. 


\section{* El autor}

Pedro Barruso Barés es Profesor Titular de Enseñanza Media. Doctor en Historia por la Universidad de Deusto y Master en Periodismo por la Universidad del País Vasco. Sus líneas de investigación se han centrado en el periodo 1931-1955 en especial en el territorio de Guipúzcoa siendo autor de más de un centenar de publicaciones. Entre sus obras más: El movimiento obrero en Guipúzcoa durante la II República (San Sebastian, Diputación Foral de Guipuzcoa, Departamento de Economía y Turismo D.L., 1996); Verano y Revolución. La Guerra Civil en Guipúzcoa (San Sebastián, Haranburu Editor, 1996); El frente silencioso: la Guerra Civil Española en el sudoeste de Francia, 1936-1940 (Alegia, Hiria, 2001). Más recientemente ha formado parte del equipo que redactó la Guía de fuentes documentales y bibliográficas sobre la Guerra Civil en el País Vasco (Vitoria, Gobierno Vasco, 2009). Ha publicado, junto con Juan Carlos Jiménez de Aberásturi, El comienzo de la Guerra Civil en Euskadi a través de los documentos diplomáticos franceses. Los informes del embajador Jean Herbette (San Sebastián: julio-octubre de 1936) (Donostia-San Sebastián, Kutxa Fundazioa D.L., 2011) y El fuerte de Guadalupe (Hondarribia) y las fortificaciones de Jaizkibel. Memoria e Historia (Hondarribia, Hondarribiko Udala, 2015).

URL: < http://www.studistorici.com/progett/autori/\#BarrusoBares >

\section{Per citare questo articolo:}

BARRUSO BARÉS, Pedro, «La guerra del comandante Troncoso. Terrorismo y espionaje en Francia durante la Guerra Civil Española», Diacronie. Studi di Storia Contemporanea : La voce del silenzio: intelligence, spionaggio e conflitto nel XX secolo, 29/12/2016,

URL:< http://www.studistorici.com/2016/12/29/barruso-bares_numero_28/ >

\section{Diacronie Studi di Storia Contemporanea $\widehat{\beta}$ www.diacronie.it}

Risorsa digitale indipendente a carattere storiografico. Uscita trimestrale. redazione.diacronie@hotmail.it

Comitato di redazione: Jacopo Bassi - Luca Bufarale - Antonio César Moreno Cantano - Deborah Paci - Fausto Pietrancosta - Alessandro Salvador - Matteo Tomasoni - Luca Zuccolo

Diritti: gli articoli di Diacronie. Studi di Storia Contemporanea sono pubblicati sotto licenza Creative Commons 3.0. Possono essere riprodotti e modificati a patto di indicare eventuali modifiche dei contenuti, di riconoscere la paternità dell'opera e di condividerla allo stesso modo. La citazione di estratti è comunque sempre autorizzata, nei limiti previsti dalla legge. 